\title{
Impact of atmospheric dust emission schemes on dust production and concentration over the Arabian Peninsula
}

\author{
Christos Fountoukis $^{1}$ (1) Luis Ackermann ${ }^{1} \cdot$ Mohammed A. Ayoub $^{1} \cdot$ \\ Ivan Gladich $^{1} \cdot$ Ross D. Hoehn ${ }^{1,2} \cdot$ Adam Skillern $^{1}$
}

Received: 13 June 2016/Accepted: 14 June 2016/Published online: 21 June 2016

(C) Springer International Publishing Switzerland 2016

\begin{abstract}
This study examines the impact of two of the most advanced dust emission schemes on the predictions of the weather research and forecasting model with chemistry (WRF-Chem) over the Middle East during a summer time period. Results show significant differences between the two simulations in the spatial distribution of dust emissions as well as in their size-resolved mass discretization. The AFWA scheme simulation predicts $30 \%$ higher dust emission fluxes than the S11 module over the Arabian Peninsula (6.7 $\mu \mathrm{g} \mathrm{m}^{-2} \mathrm{~s}^{-1}$ compared to $4.5 \mu \mathrm{g} \mathrm{m}^{-2} \mathrm{~s}^{-1}$, respectively). In the S11 simulation $70 \%$ of the emitted dust is in the 10-20 $\mu \mathrm{m}$ size range while the AFWA simulation assigns $50 \%$ of dust emitted particles in the $6-12 \mu \mathrm{m}$ size section. Both simulations reproduce the majority of the ambient $\mathrm{PM}_{10}$ data (more than $70 \%$ ) within a factor of two. However, the S11 simulation predicts, on average, $50 \%$ lower $\mathrm{PM}_{10}$ concentrations compared to AFWA over the high resolution $\left(2 \times 2 \mathrm{~km}^{2}\right)$ domain of Qatar. Previous applications of WRF-Chem may have substantially overestimated the simulated dust in this region.
\end{abstract}

Keywords Atmospheric particulate matter - WRF-Chem . Chemical transport modeling - Aerosol size distribution

Christos Fountoukis

cfountoukis@qf.org.qa

1 Qatar Environment and Energy Research Institute (QEERI), Hamad Bin Khalifa University (HBKU),

P.O. Box 5825, Doha, Qatar

2 Department of Chemistry, Purdue University, West Lafayette, IN, USA

\section{Introduction}

Mineral dust plays a pivotal role in atmospheric processes affecting climate and the environment and therefore has been identified as an emerging key theme in Earth Science. In arid and semi-arid regions a large part of $\mathrm{PM}_{10}$ (particulate matter with aerodynamic diameter less than $10 \mu \mathrm{m})$ is comprised of crustal material from dust emissions (Tsiouri et al. 2015). Dust aerosols can either originate locally or transported from thousands of kilometers away (Prospero et al. 2002). Once the wind velocity exceeds a threshold, particles are vibrated and lifted into the air through the "saltation" transport process. High levels of dust concentration and deposition can also negatively affect solar power generation in regions where photovoltaic systems are installed due to dust-induced shading, degrading PV efficiency (Mani and Pillai 2010).

Several atmospheric models have been applied to study the dispersion and physicochemical processes of dust particles in certain regions of the world; model results, however, exhibit large variation especially regarding the spatial distribution of dust concentrations. Eastern Asia (Wang et al. 2012; Su and Fung 2015) and the Middle East are two areas largely affected by high dust loads in the atmosphere. In the Middle East, however, the limited number of published ambient monitoring studies makes it difficult to assess and evaluate model predictions. Prakash et al. (2015) used the "online" meteorological and chemical transport weather research and forecasting/chemistry (WRF-Chem) model to study the effect of dust events in the Arabian Peninsula on radiation fluxes and regional climate characteristics. Using the same model, Kalenderski et al. (2013) simulated a typical winter-time dust event over the Arabian Peninsula and the Red Sea and found that 
the total amount of emitted dust was $18.3 \mathrm{Tg}$ for the entire dust outburst period.

In this study we use the 3-D regional meteorologychemistry model WRF-Chem (Grell et al. 2005; Fast et al. 2006). We cover the Arabian Peninsula with a triple-nested domain configuration with the highest grid resolution over the region of Qatar. We focus on dust emissions and concentrations and unlike previous WRF-Chem applications in this region (Prakash et al. 2015; Kalenderski et al. 2013) we utilize the two latest dust emission schemes incorporated in the WRF-Chem model; namely (1) the AFWA (Air Force Weather Agency) and (2) the S11 (Shao et al. 2011) emission schemes. We finally evaluate the model predictions of $\mathrm{PM}_{10}$ concentrations with ambient data collected from a monitoring station at Doha, Qatar.

\section{Methodology}

\section{Model application}

WRF-Chem is based on the WRF model, a meso-scale nonhydrostatic meteorological model that includes several options for physical parameterizations of cloud processes, planetary boundary layer and land surface. The options that are used in this work include the Lin microphysics scheme (Chen and Sun 2002), the Grell 3D cumulus parameterization (Grell and Devenyi 2002), the Yonsei University boundary layer scheme (Hong et al. 2006), the 5-layer thermal diffusion Land Surface Model, the revised MM5 MoninObukhov surface layer scheme, the Rapid Radiative Transfer Model longwave radiation scheme (Mlawer et al. 1997) and the Goddard shortwave radiation scheme (Chou et al. 1998).

Dust is simulated in this work using two different emission scheme options, both of which generate dust emissions "online" during the WRF-Chem run; (1) the AFWA emission scheme adopted from the Georgia Institute of Technology-Goddard Global Ozone Chemistry Aerosol Radiation and Transport (GOCART) model (Ginoux et al. 2001), and, (2) the S11 (Shao et al. 2011) emission scheme. The AFWA emissions scheme is an integration of the semiempirical MB95 dust emission parameterization (Marticorena and Bergametti 1995) with the Kok (2011) airborne dust size distributions and predicts bulk dust fluxes which are then distributed to the size-resolved sections according to observed dust size distributions. The bulk dust flux in the AFWA scheme is calculated as follows:

$F=a E c \frac{\rho_{\alpha}}{g} u_{*}^{3}\left(1+\frac{u_{* t}}{u_{*}}\right)\left(1-\frac{u_{* t}^{2}}{u_{*}^{2}}\right)$,

where $\alpha$ is the sandblasting efficiency, $E$ is the erodibility factor (Ginoux et al. 2001), $c$ is an empirical proportionality constant, $\rho_{\alpha}$ is the air density, $g$ is the gravitational acceleration constant, $u_{*}$ is the friction velocity and $u_{* t}$ is the threshold friction velocity. The S11 scheme is a physical-based dust emission parameterization that explicitly represents the dust emission processes of saltation and aggregate disintegration, thus directly predicting size-resolved dust fluxes. The S11 dust fluxes are determined by:

$F\left(d_{i} ; d_{s}\right)=c_{y} \eta_{f i} g \sigma_{p}\left(1+\sigma_{m}\right) \frac{Q_{d s}}{u_{*}^{2}}$,

where $F\left(d_{i} ; d_{s}\right)$ is the dust emission rate of $d_{i}$-sized particles produced by the saltation of $d_{s}$-sized particles, $c_{y}$ is a dimensionless coefficient, $\eta_{f i}$ is the fraction of dust that can be injected into the atmosphere, $\sigma_{p}$ is the ratio between the fraction of free dust and that of aggregated dust, $\sigma_{m}$ is the bombardment efficiency and $Q_{d s}$ is the saltation flux of $d_{s^{-}}$ sized particles.

In this study the WRF-Chem model version 3.7 is applied over the Middle Eastern Area (MEA) simulating the emission, transport, turbulent mixing, transformation, and aging of trace gases and aerosols on a domain of nested three-dimensional grids. The extended domain covering MEA (d01) uses a $50 \times 50 \mathrm{~km}^{2}$ resolution and the intermediate domain (d02), focusing on the Arabian desert, $10 \times 10 \mathrm{~km}^{2}$, while the state of Qatar (d03) is resolved on a $2 \times 2 \mathrm{~km}^{2}$ gridded domain (Fig. 1). All three domains use 28 vertical layers from the surface up to $50 \mathrm{hPa}$. The model runs simulate the period between 21 June, 2015 and

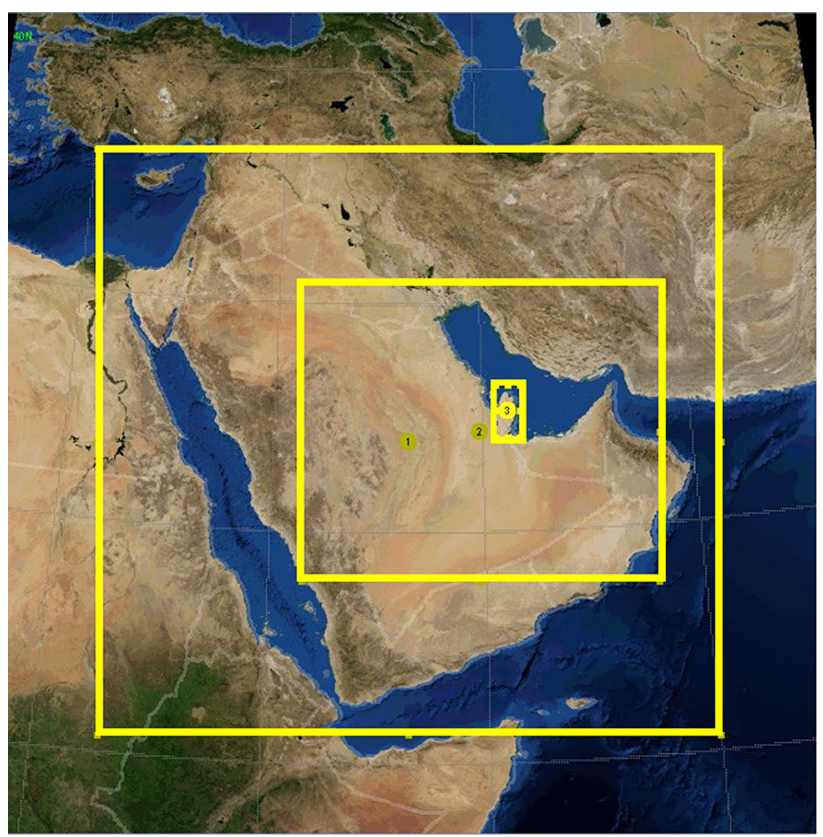

Fig. 1 Modeling domain of WRF-Chem for the Middle East in a triple nested configuration 
(a)

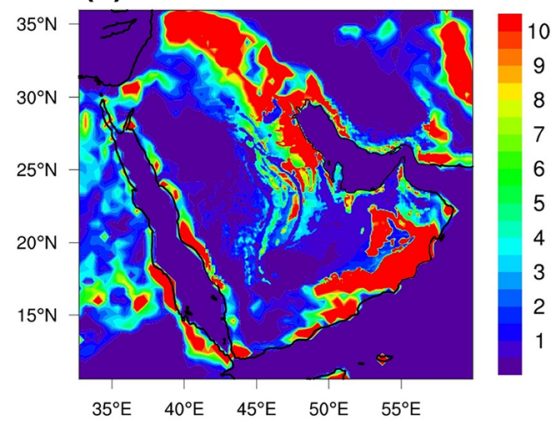

(b)

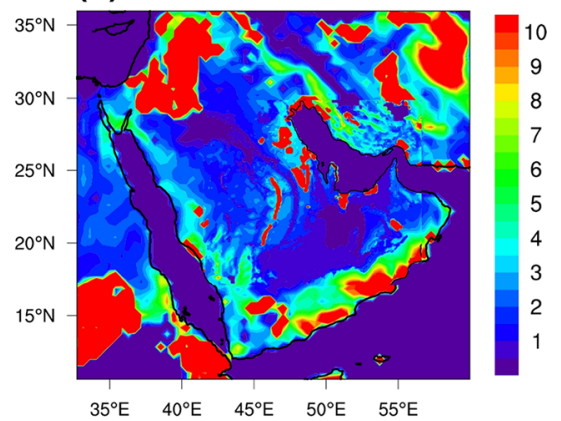

(c)

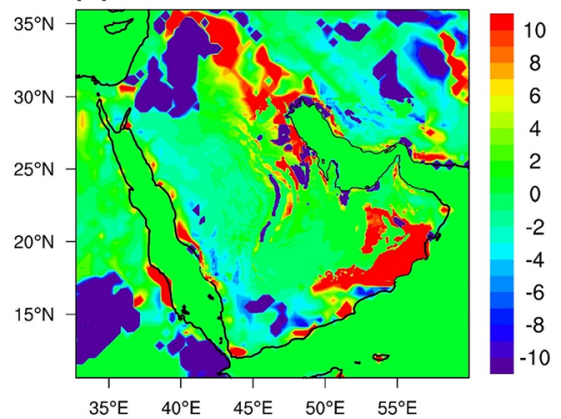

Fig. 2 Monthly average simulated (WRF-Chem) spatial distribution of dust emission flux (in $\mu \mathrm{g} \mathrm{m}^{-2} \mathrm{~s}^{-1}$ ) in MEA during July 2015 at the ground level, a with the AFWA scheme, $\mathbf{b}$ the S11 scheme and, $\mathbf{c}$ the difference between AFWA and S11

31 July, 2015. WRF-Chem was set to perform simulations on a lambert map projection. The first 10 days of each simulation are considered spin-up time and excluded from the analysis to limit the effect of initial conditions on the results. The GOCART chemistry mechanism is used in all simulations while no anthropogenic emissions are considered.

\section{Ambient data}

Prevalent air constituents and meteorological parameters are measured continuously at ground level in Doha, Qatar at the Air Quality Monitoring Site (AQMS) located inside the Education City (lat: 25.2182; lon: 51.4331) and operated by the Qatar Environment and Energy Research Institute (QEERI). The site is representative of urban background air quality. A particulate matter (PM) analyzer (MP101 M) is used to measured $\mathrm{PM}_{10}$ concentrations hourly during July 2015. This instrument measures the amount of radiation a sample absorbs when exposed to a radioactive source; absorption is a function of the mass of the irradiated material. Continuous measurements (every $1 \mathrm{~min}$ ) of temperature and relative humidity are conducted using a Thermo-hygrometer (DMA867-875) and the ground-level wind speed and direction are determined using an Anemometer (DNA827).

\section{Results and discussion}

Figure 2 shows the monthly average spatial distribution of dust emission flux during July 2015 over MEA at the ground level; (1) with the AFWA scheme, (2) the S11 scheme, and, (3) the difference between the two. Significant spatial differences in the emitted dust are predicted between the two schemes in certain areas of the region. The S11 scheme predicts higher concentrations in northeastern Africa, parts of Jordan, Syria and Iraq, as well as in

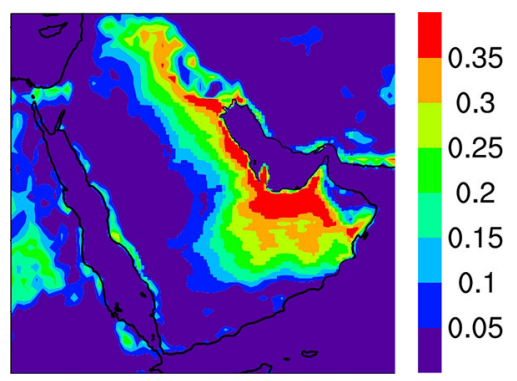

Fig. 3 Dust erodibility factor (dimensionless) from the AFWA scheme simulation

northern and eastern Saudi Arabia, Iran and Yemen by up to $300 \mu \mathrm{g} \mathrm{m}^{-2} \mathrm{~s}^{-1}$. On the contrary, the AFWA scheme predicts emission fluxes much higher than the S11 scheme (by up to $400 \mu \mathrm{g} \mathrm{m}^{-2} \mathrm{~s}^{-1}$ ) in parts of Iraq, Oman, eastern Saudi Arabia and across the coast of the Red Sea. Both schemes predict similar emissions for the remainder of the Arabian Peninsula with differences of approximately $\pm 10 \mu \mathrm{g} \mathrm{m}^{-2} \mathrm{~s}^{-1}$. The $\mathrm{S} 11$ scheme predicts approximately $30 \%$ lower monthly average dust emissions over the Arabian Peninsula (d02) compared to the AFWA scheme $\left(4.5 \mu \mathrm{g} \mathrm{m}^{-2} \mathrm{~s}^{-1}\right.$ compared to $6.7 \mu \mathrm{g} \mathrm{m}^{-2} \mathrm{~s}^{-1}$, respectively). Interestingly, the AFWA scheme simulation unlike the S11 scheme predicts much lower dust emission fluxes in all the western part of the Arabian Peninsula as compared to the eastern part. This is because of the substantially lower erodibility over this region (Fig. 3) and the fact that the AFWA scheme directly scales the dust flux based on the fraction of erodible surface, while the S11 scheme uses the erodibility data only to constrain the type of potential emission areas (land/sea distinction). It should be noted that the proportionality constant, $c$ (Eq. 1), of the AFWA simulation was set to a value, representative for the Arabian Peninsula, of 0.4 as suggested by Kalenderski et al. (2013). Studies have shown that $c$ can range from 0.4 to 0.65 (Zhao et al. 2010; Su and Fung 2015) to accommodate various regions of the world. The AFWA 
(a)

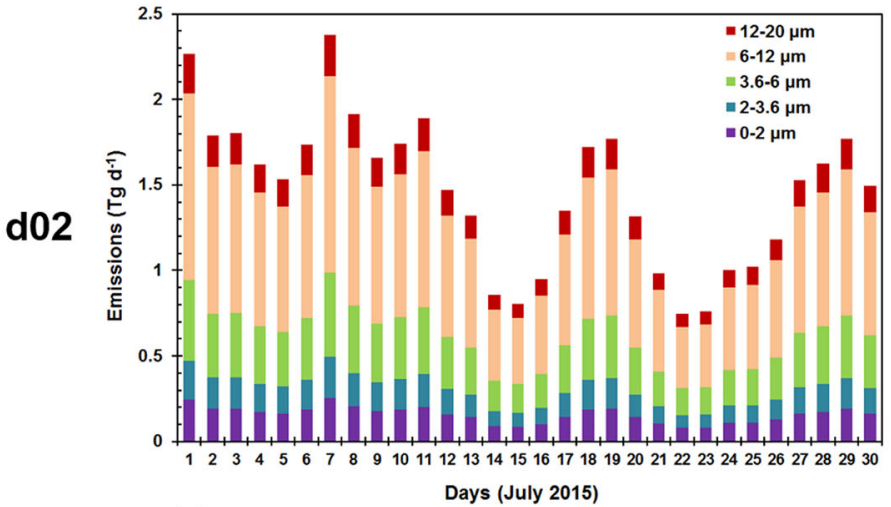

(c)

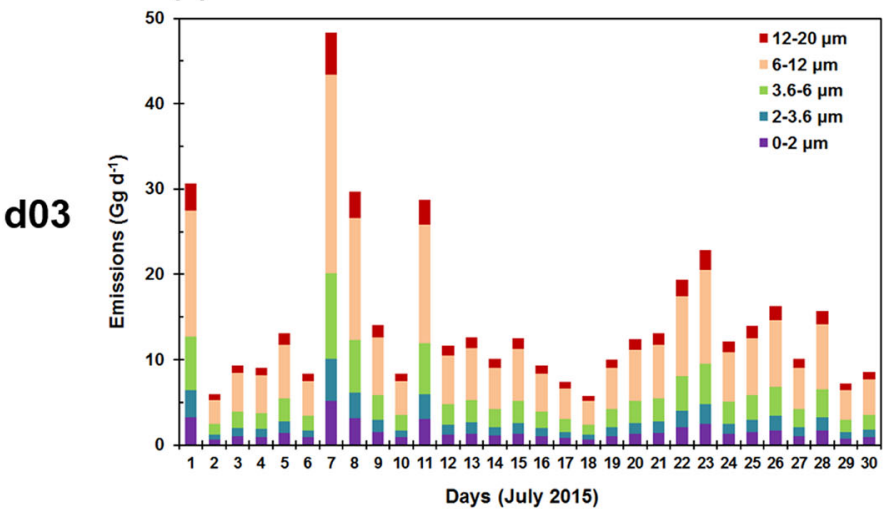

(b)

S11

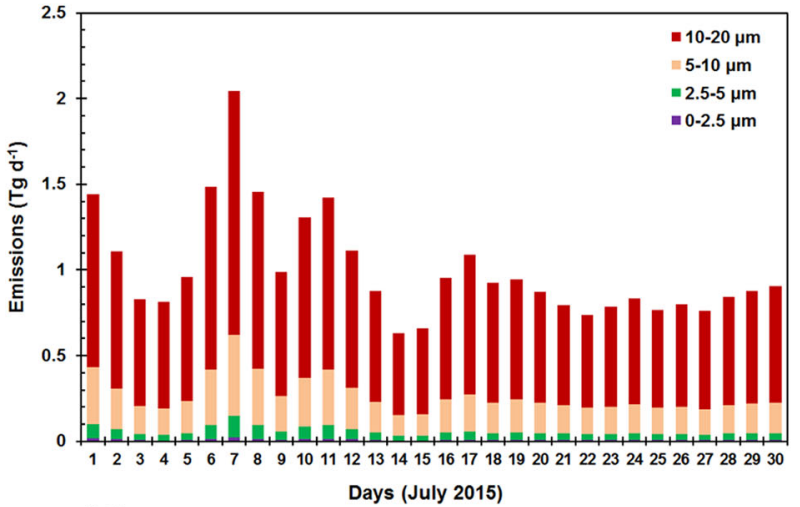

(d)

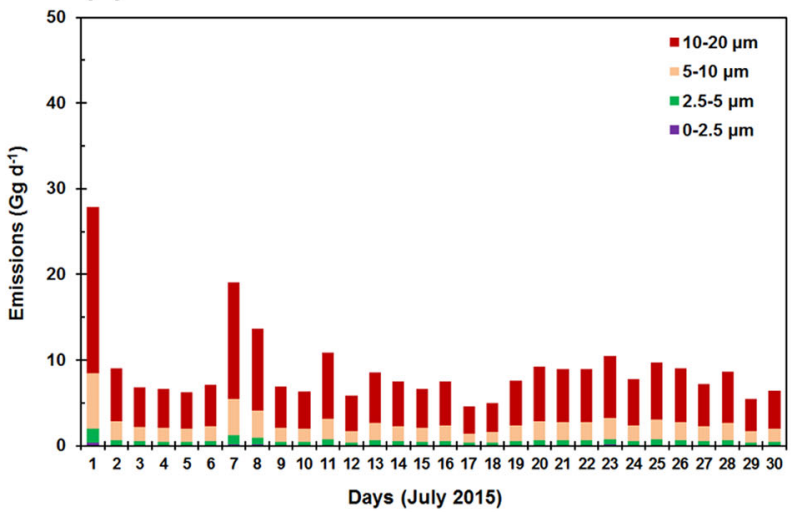

Fig. 4 24-hr average dust emissions simulated over the Arabian Peninsula (top panels) and the state of Qatar (bottom panels) for each size bin with the AFWA (a, c) and the S11 (b, d) dust schemes of WRF-Chem

simulation results, shown in Fig. 2a, are comparable with Kalenderski et al. (2013) who used the Ginoux et al. (2001) dust emission flux scheme of the GOCART model (without the AFWA modifications).

The daily averaged size distribution of emissions with the two schemes over the Arabian Peninsula (d02) and state of Qatar (d03) regions are shown in Fig. 4. The AFWA scheme distributes dust emissions over the aerosol size spectrum much differently than does the S11 scheme in both domains. The AFWA scheme predicts that almost $50 \%$ of its dust emissions are in the $6-12 \mu \mathrm{m}$ size bin and only $10 \%$ in the $12-20 \mu \mathrm{m}$ range. The S11 scheme on the other hand, predicts the majority ( $70 \%$ ) of the emitted dust to be in the $10-20 \mu \mathrm{m}$ range followed by $20 \%$ in the $5-10 \mu \mathrm{m}$ size bin while only $1 \%$ are within the $0-2.5 \mu \mathrm{m}$ size regime. The 24-h average emission predicted by S11 is 8.9 $\mathrm{Gg}_{\text {day }}{ }^{-1}$ over Qatar and $1 \mathrm{Tg}$ day $^{-1}$ over the Arabian Peninsula while the AFWA scheme simulation predicts 14.5 $\mathrm{Gg}$ day $^{-1}$ and $1.5 \mathrm{Tg} \mathrm{day}^{-1}$ for Qatar and the Arabian Peninsula, respectively. The two schemes show many similarities in the temporal distribution of emissions. Over Qatar, both schemes predict the highest emissions during July 1 and 7 and the lowest on July 17 and 18 .
Interestingly, over the Arabian Peninsula, July 1 and 7 are also among the highest dust emitted days in both simulations. The lowest emissions over Qatar are predicted by both simulations on 17 and 18 July but over the Arabian Peninsula both schemes still predict high emissions during
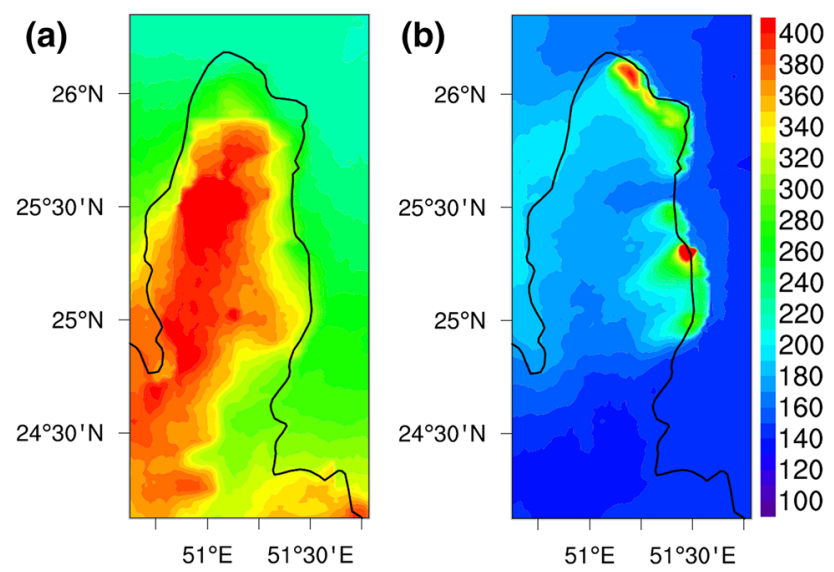

Fig. 5 Average (median) predicted spatial distribution of $\mathrm{PM}_{10}$ concentration (in $\mu \mathrm{g} \mathrm{m}^{-3}$ ) in Qatar during July 2015 at the ground level with: a the AFWA scheme and, b the S11 scheme of WRFChem 

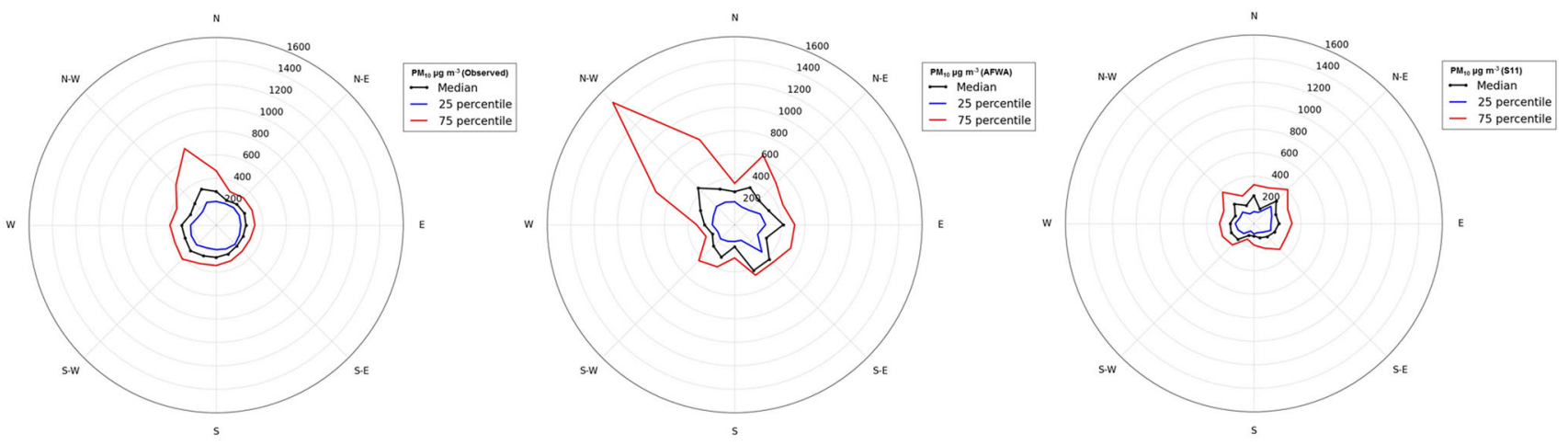

Fig. 6 Correlation plots of $\mathrm{PM}_{10}$ concentration vs wind direction during July 2015 at the QEERI monitoring site in Doha, Qatar

these days. The implications of this suggest that some dust events occurring within Qatar are most attributable to medium-to-long range transport while some others are induced locally.

Figure 5 shows the spatial distribution of the monthly median $\mathrm{PM}_{10}$ concentration predicted by WRF-Chem over Qatar with the two different dust emission modules. As expected the results of the two simulations show differences in the distribution of particle concentrations. Overall, the AFWA scheme predicts substantially higher $\mathrm{PM}_{10}$ concentrations over the state of Qatar (by approximately $50 \%$ on average) compared to the S11 simulation. By directly scaling the dust emission flux to the erodibility data, the AFWA module predicts elevated $\mathrm{PM}_{10}$ concentrations, ranging between 300 and $600 \mu \mathrm{g} \mathrm{m}^{-3}$ over the mainland of Qatar within the basin of the Qatari desert. The S11 simulation results however show a very different situation. The model predicts $\mathrm{PM}_{10}$ concentrations significantly lower (100-200 $\mu \mathrm{g} \mathrm{m}^{-3}$ ) compared to AFWA over the mainland and somewhat higher (more than $300 \mu \mathrm{g} \mathrm{m}^{-3}$ ) across the east coast of the country. This is because the S11 scheme is more sensitive to the wind profiles rather than the erodibility data. During July strong sea breeze circulation develops on the east coast of Qatar lifting more dust particles in the air over this part of the country (Fig. 5b). The intense $\mathrm{PM}_{10}$ levels over the city center of Doha predicted by WRF-Chem with the S11 module could be attributed to the increased fractional area covered by roughness elements which lowers the threshold friction velocity for particle mobilization.

Correlation plots of $\mathrm{PM}_{10}$ concentrations with wind direction are shown in Fig. 6 as predicted by the two simulations and measured at the QEERI monitoring station. The AFWA scheme simulation results are closer to the observations predicting the majority of $\mathrm{PM}_{10}$ to originate from N-NW winds. With regard to $\mathrm{PM}_{10}$ concentrations only, both emission schemes perform well (considering the high time resolution of the data comparison), reproducing the majority of the data (more than $70 \%$ ) within a factor of

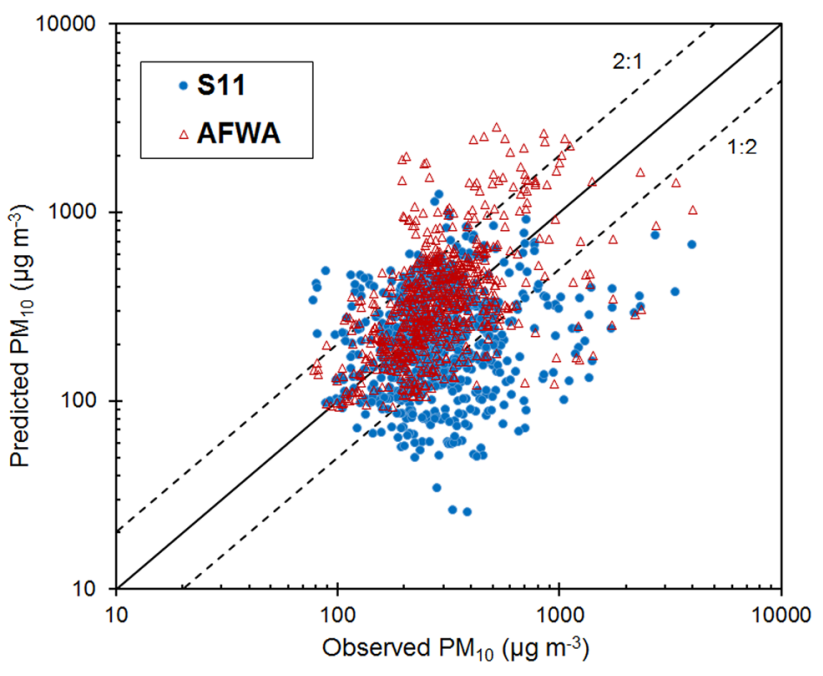

Fig. 7 Scatter plot of predicted (AFWA with red triangles and S11 with blue dots) vs. observed $\mathrm{PM}_{10}$ concentrations (hourly data) at the QEERI monitoring site in Doha, Qatar

two (Fig. 7). The AFWA simulation overestimates the $\mathrm{PM}_{10}$ concentrations with a mean bias $(\mathrm{MB})=80 \mu \mathrm{g} \mathrm{m}^{-3}$ and a fractional error (FERROR) of 0.4. This could be an indication that the empirical proportionality constant value of $c=0.4$ might not be appropriate for this region of the Arabian Peninsula; a lower value is most likely a better choice (e.g. $\mathrm{c}=0.3)$. The $\mathrm{S} 11$ simulation shows somewhat larger systematic errors $\left(\mathrm{MB}=-70 \mu \mathrm{g} \mathrm{m}^{-3}\right.$, FER$\mathrm{ROR}=0.5$ ) than the AFWA run, mainly under predicting the observed $\mathrm{PM}_{10}$ concentrations. However, it should be noted that this site, located close to a city center, experiences the influence of anthropogenic emissions, and thus the inclusion of such emissions in the model's input is expected to further improve the model's performance for the S11 scheme. This work highlights the necessity for more ambient data published from the Middle East in order to evaluate the ability of such emission schemes to reproduce observed particulate matter concentrations. 


\section{Conclusions}

This study focuses on the application of a 3-D regional chemical transport model over the Middle East with a high grid resolution over the state of Qatar during a summer time period. We test the sensitivity of the predictions from the two latest and most advanced dust emission schemes within the model. A number of important conclusions arise from this study:

1. The model predicts significant differences in the spatial distribution of dust production over the Middle Eastern domain. The S11 scheme simulation predicts, on average, $30 \%$ lower dust emission fluxes than the AFWA simulation.

2. The erodibility factor within the AFWA scheme is most likely underestimated across the western part of the Arabian Peninsula suggesting the need for updated erodibility data sets.

3. Both schemes show similar patterns in the temporal distribution of total dust emissions but significant differences in the particle size distributions. The S11 simulation assigns $70 \%$ of the emitted dust in the $10-20 \mu \mathrm{m}$ size range and less than $1 \%$ in the $0-2.5 \mu \mathrm{m}$ bin while the AFWA simulation predicts that the majority $(50 \%)$ of dust is emitted in the 6-12 $\mu \mathrm{m}$ size section and $10 \%$ at the $0-2 \mu \mathrm{m}$ range.

4. The S11 scheme predicts substantially lower $\mathrm{PM}_{10}$ concentrations (by approximately $50 \%$ on average) compared to the AFWA scheme over the State of Qatar.

5. The AFWA scheme performs somewhat better than the S11 scheme while a lower value of the empirical proportionality constant, $c$, seems more representative of Qatar. Previous applications of WRF-Chem with the AFWA or the similar Ginoux et al. (2001) scheme may have substantially overestimated the simulated dust in this region.

Acknowledgments We acknowledge the logistic support of Hamad Bin Khalifa University and Qatar Foundation for making this study possible. We thank Dr. Khalid Al-Subai, Acting Executive Director of QEERI, and Dr. Aurora M. Castilla for their useful comments. We would like to thank the Solar Energy Group in QEERI for providing space in the solar test facility for the installation of the QEERI monitoring station.

\section{References}

Chen SH, Sun WY (2002) A one-dimensional time dependent cloud model. J Meteor Soc Jpn 80:99-118

Chou MD, Suarez MJ, Ho CH, Yan MMH, Lee KT (1998) Parameterizations for cloud overlapping and shortwave singlescattering properties for use in general circulation and cloud ensemble models. J Clim 11:202-214

Fast JD, Gustafson WI Jr, Easter RC, Zaveri RA, Barnard JC, Chapman EG, Grell GA (2006) Evolution of ozone, particulates, and aerosol direct forcing in an urban area using a new fullycoupled meteorology, chemistry, and aerosol model. J Geophys Res 111:D21305. doi:10.1029/2005JD006721

Ginoux P, Chin M, Tegen I, Prospero JM, Holben B, Dubovik O, Lin SJ (2001) Sources and distributions of dust aerosols simulated with the GOCART model. J Geophys Res 106(D17):20255-20273. doi:10.1029/2000JD000053

Grell GA, Devenyi D (2002) A generalized approach to parameterizing convection combining ensemble and data assimilation techniques. Geophys Res Lett 29:1693. doi:10.1029/ 2002GL015311

Grell GA, Peckham SE, Schmitz R, McKeen SA, Frost G, Skamarock WC, Eder B (2005) Fully coupled "online" chemistry within the WRF model. Atmos Environ 39(37):6957-6975

Hong S, Noh Y, Dudhia J (2006) A new vertical diffusion package with an explicit treatment of entrainment processes. Mon Weather Rev 134:2318-2341

Kalenderski S, Stenchikov G, Zhao C (2013) Modeling a typical winter-time dust event over the Arabian Peninsula and the Red Sea. Atmos Chem Phys 13:1999-2014. doi:10.5194/acp-131999-2013

Kok JF (2011) A scaling theory for the size distribution of emitted dust aerosols suggests climate models underestimate the size of the global dust cycle. Proc Natl Acad Sci 108(3):1016-1021

Mani M, Pillai R (2010) Impact of dust on solar photovoltaic (PV) performance: research status, challenges and recommendations. Renew Sustain Energy Rev 14:3124-3131. doi:10.1016/j.rser. 2010.07.065

Marticorena B, Bergametti G (1995) Modeling the atmospheric dust cycle. 1. Design of a soil-derived dust emission scheme. J Geophys Res 100(D8):16415-16430. doi:10.1029/95JD00690

Mlawer EJ, Taubman SJ, Brown PD, Iacono MJ, Clough SA (1997) Radiative transfer for inhomogeneous atmospheres: RRTM, a validated correlated-k model for the longwave. J Geophys Res 102:16663-16682

Prakash PJ, Stenchikov G, Kalenderski S, Osipov S, Bangalath H (2015) The impact of dust storms on the Arabian Peninsula and the Red Sea. Atmos Chem Phys 15:199-222. doi:10.5194/acp15-199-2015

Prospero JM, Ginoux P, Torres O, Nicholson SE, Gill TE (2002) Environmental characterization of global sources of atmospheric soil dust identified with the Nimbus 7 total ozone mapping spectrometer (TOMS) absorbing aerosol product. Rev Geophys 40:1002. doi:10.1029/2000RG000095

Shao Y, Ishizuka M, Mikami M, Leys JF (2011) Parameterization of size-resolved dust emission and validation with measurements. J Geophys Res 116:D08203. doi:10.1029/2010JD014527

Su L, Fung JCH (2015) Sensitivities of WRF-Chem to dust emission schemes and land surface properties in simulating dust cycles during springtime over East Asia. J Geophys Res. doi:10.1002/ 2015JD023446

Tsiouri V, Kakosimos KE, Kumar P (2015) Concentrations, sources and exposure risks associated with particulate matter in the Middle East Area-a review. Air Qual Atmos Health 8:67-80. doi:10.1007/s11869-014-0277-4

Wang K, Zhang Y, Nenes A, Fountoukis C (2012) Implementation of dust emission and chemistry into the community multiscale air quality modeling system and initial application to an Asian dust storm episode. Atmos Chem Phys 12:10209-10237. doi:10. 5194/acp-12-10209-2012

Zhao C, Liu X, Leung LR, Johnson B, McFarlane SA, Gustafson WI $\mathrm{Jr}$, Fast JD, Easter R (2010) The spatial distribution of mineral dust and its shortwave radiative forcing over North Africa: modeling sensitivities to dust emissions and aerosol size treatments. Atmos Chem Phys 10(18):8821-8838. doi:10.5194/ acp-10-8821-2010 